\title{
Vertical profile of atmospheric dimethyl sulfide in the Arctic Spring and Summer
}

\section{Roghayeh Ghahremaninezhad', Ann-Lise Norman', Betty Croft ${ }^{2}$, Randall V.}

Martin $^{2}$, Jeffrey R. Pierce ${ }^{3}$, Julia Burkart ${ }^{4}$, Ofelia Rempillo1, Heiko Bozem ${ }^{5}$, Daniel Kunkel ${ }^{5}$, Jennie L. Thomas ${ }^{6}$, Amir A. Aliabadi ${ }^{7}$, Gregory R. Wentworth $^{4}$, Maurice Levasseur ${ }^{8}$, Ralf M. Staebler ${ }^{9}$, Sangeeta Sharma ${ }^{9}$ and W. Richard Leaitch ${ }^{9}$

[1] Department of Physics and Astronomy, University of Calgary, Calgary, Canada

[2] Department of Physics and Atmospheric Science, Dalhousie University, Halifax, Canada

[3] Department of Atmospheric Science, Colorado State University, Fort Collins, USA

[4] Department of Chemistry, University of Toronto, Toronto, Canada

[5] Institute of Atmospheric Physics, University of Mainz, Mainz, Germany

[6] Sorbonne Universités, UPMC Univ. Paris 06, Universite Versailles St-Quentin, CNRS/INSU, UMR8190, LATMOS-IPSL, Paris, France

[7] Environmental Engineering Program, School of Engineering, University of Guelph, Guelph, Canada

[8] Department of Biology, Laval University, Quebec, Canada

[9] Environment and Climate Change Canada, Toronto, Canada

Corresponding author: Ann-Lise Norman (alnorman@ucalgary.ca) 


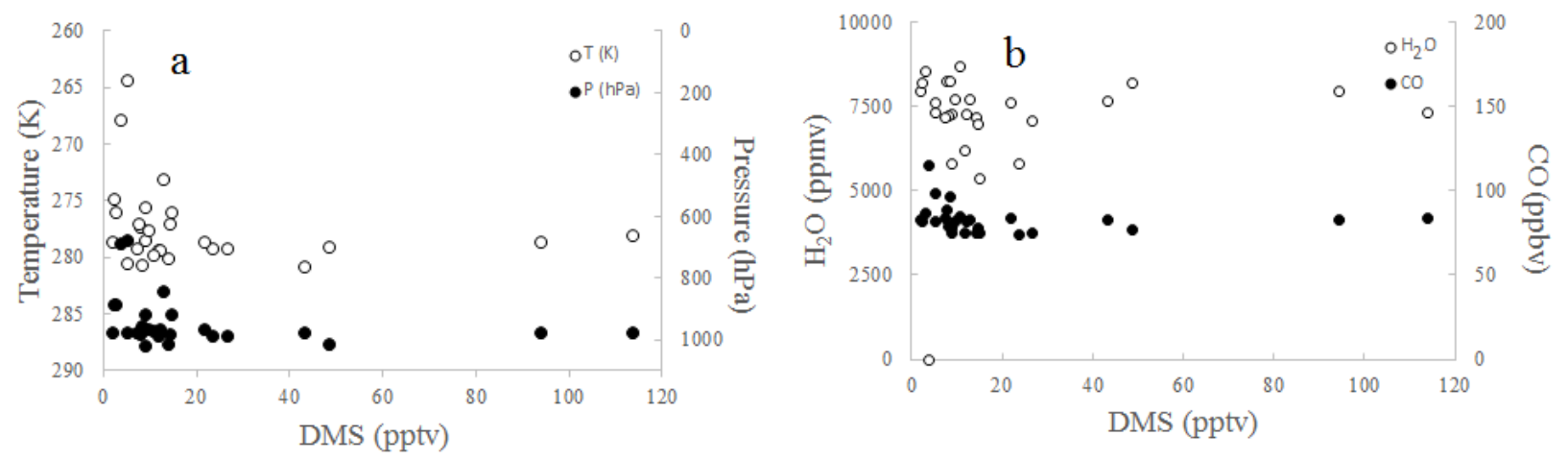

Figure $\mathrm{S} 1$. Temperature $(\mathrm{K})$ and pressure (hPa) versus DMS mixing ratio (pptv) (a), $\mathrm{H}_{2} \mathrm{O}$ (ppmv) and CO (ppbv) mixing ratios versus DMS mixing ratio (pptv) (b) during July 2014. Closed circles are used to show pressure and $\mathrm{CO}$ mixing ratios, and open circles are used to show temperature and $\mathrm{H}_{2} \mathrm{O}$ mixing ratios. There was no correlation in July $2014\left(\mathrm{R}^{2}=0.04\right)$ between DMS mixing ratios and pressure. 


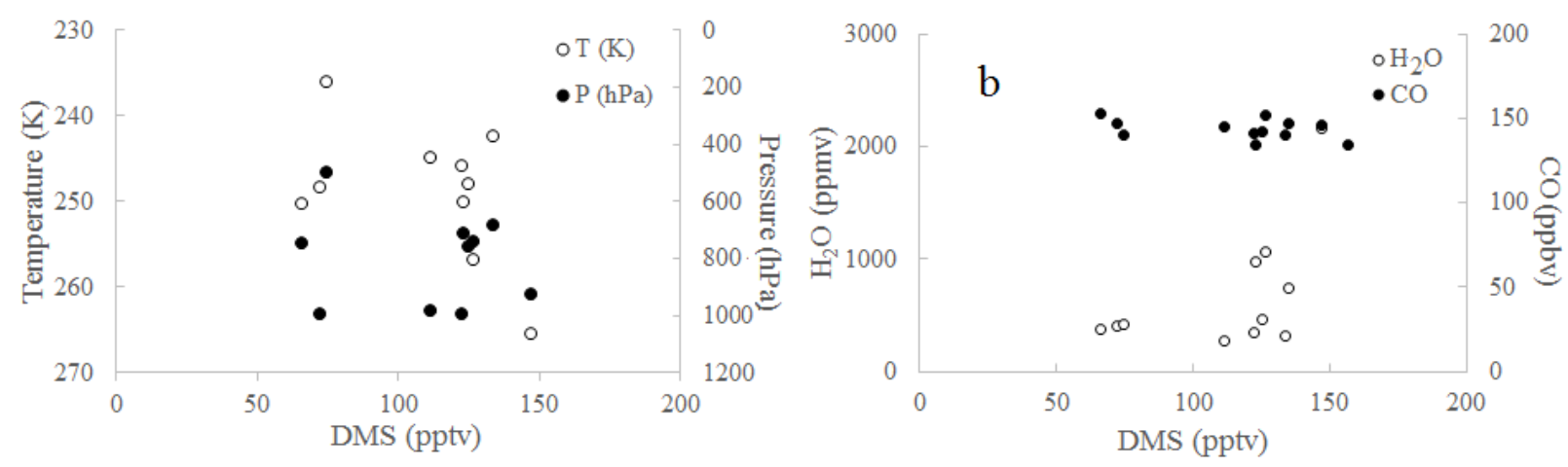

Figure $\mathrm{S} 2$. Temperature $(\mathrm{K})$ and pressure $\left(\mathrm{hPa}\right.$ ) versus DMS mixing ratio (pptv) (a), $\mathrm{H}_{2} \mathrm{O}$ (ppmv) and CO (ppbv) mixing ratios versus DMS mixing ratio (pptv) (b) during April 2015. Closed circles are used to show pressure and $\mathrm{CO}$ mixing ratios, and open circles are used to show temperature and $\mathrm{H}_{2} \mathrm{O}$ mixing ratios. There was a weak correlation in April $2015\left(\mathrm{R}^{2}=0.17\right)$ between DMS mixing ratios and pressure. 

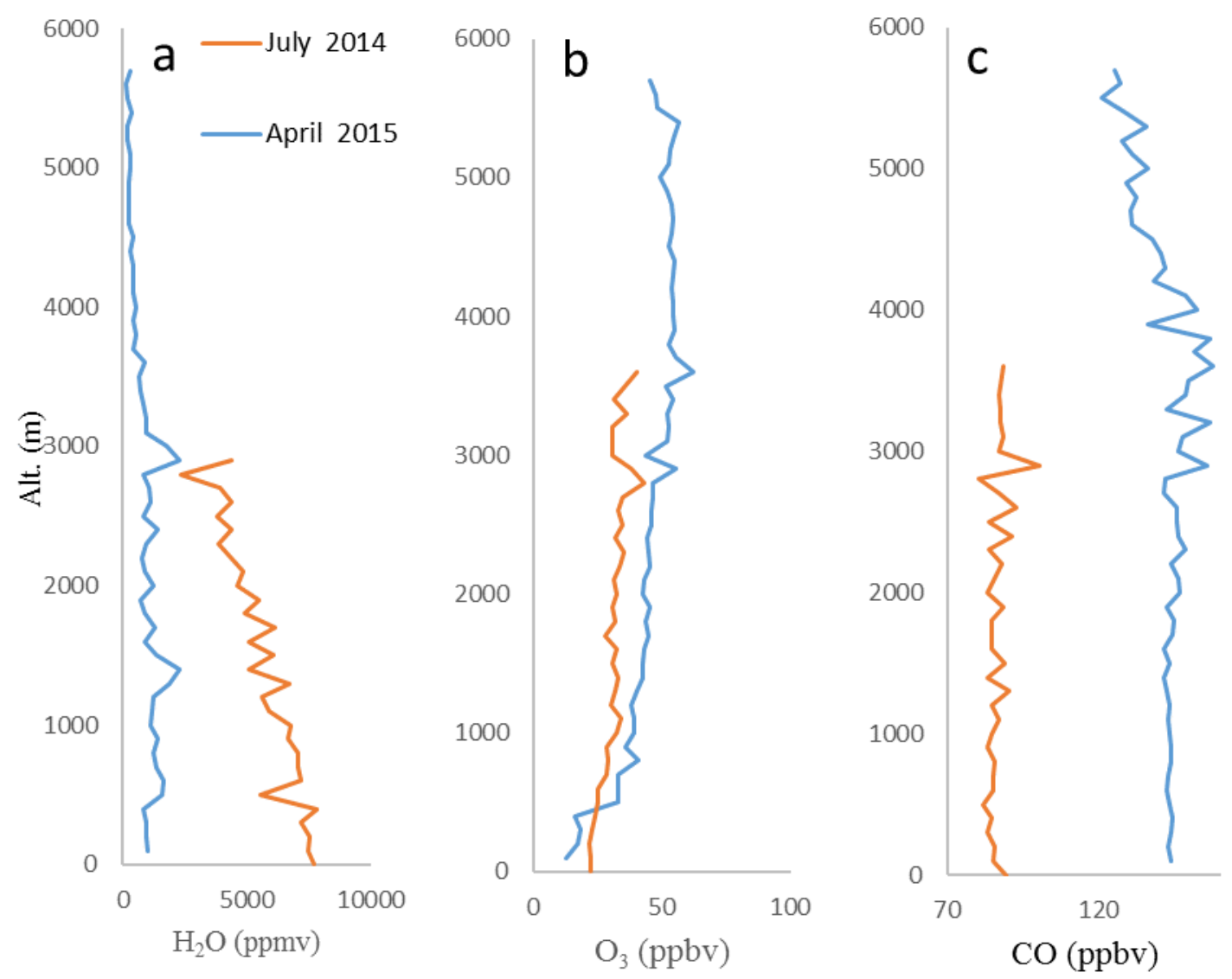

Figure S3. Average vertical profile of $\mathrm{H}_{2} \mathrm{O}(\mathrm{g})$ (a) and $\mathrm{O}_{3}$ (b) and $\mathrm{CO}$ (c) during July 2014 (orange) and April 2015 (blue). 


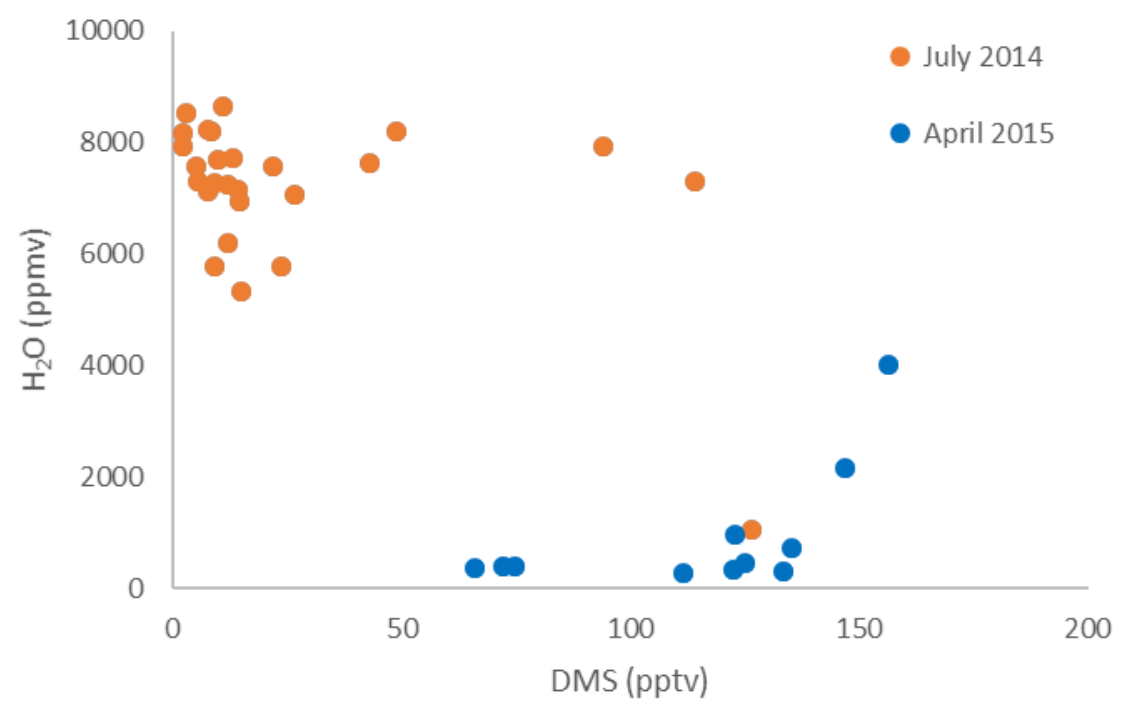

Figure S4. Concurrent measurements of $\mathrm{H}_{2} \mathrm{O}(\mathrm{g})$ versus DMS for July 2014 (orange) and April 2015 (blue) campaigns. 